Please quote as: Dünnebeil, S.; Sunyaev, A.; Leimeister, J. M. \& Krcmar, H. (2010): Strategies for Development and Adoption of EHR in German Ambulatory Care. In: 4th International Conference on Pervasive Computing Technologies for Healthcare 2010, Munich, Germany. 


\title{
Strategies for Development and Adoption of EHR in German Ambulatory Care
}

\author{
Sebastian Duennebeil ${ }^{1}$, Ali Sunyaev ${ }^{1}$, Jan Marco Leimeister ${ }^{2}$, Helmut Krcmar ${ }^{1}$ \\ ${ }^{1}$ Department of Informatics \\ ${ }^{1}$ Technische Universität München \\ Germany \\ \{duennebe|sunyaev|krcmar\}@in.tum.de \\ ${ }^{2}$ Department of Economics \\ ${ }^{2}$ Universität Kassel \\ Germany \\ leimeister@uni-kassel.de
}

\begin{abstract}
Electronic Health Records (EHR) have the potential to improve the delivery of health care. In Germany most physicians in ambulatory care have adopted Electronic Medical Records (EMR) locally within their institutions, using their practice information systems. A national telematics initiative, which connects various local medical information systems via a common infrastructure, aims to achieve integrated care, supported by comprehensive, citizen controlled medical documentation. This requires the adoption of connected EHR which leads to several technical, organizational, and psychological barriers. In early 2009, we conducted a survey of 117 physicians, representing a response rate of $23 \%$, to investigate requirements for national EHR initiatives. We evaluated the preferred content of EHR, diffusion methods favored by care providers, and the desired level of patient involvement. Results indicate that private companies and government related organizations show little support among the physicians; the preferred institutions for hosting and offering electronic health services (EHS) as EHR are medical associations and physician networks. They are also the preferred source for information concerning EMS. Medication, allergies and intolerances are reported to be of capital importance for physicians, while shared documentation of diagnosis and examination results raise the highest rate of skepticism. It is mainly the patient centered administration of EHR that is wanted, albeit still with skepticism.
\end{abstract}

Keywords- Ambulatory Care; Patient Data; Healthcare Telematics Infrastructure; Electronic Health Record; Personal Health Records; National Telemedicin Initiative

\section{INTRODUCTION}

Health information systems have the potential to improve healthcare quality [1]. Accordingly, German health authorities are currently building a nationwide telematics infrastructure (TI) to connect care providers' information systems via a common network [2]. Telemedicine services will offer communication, cooperation and documentation features as web services to ensure pervasive availability and integrity of medical data among the public health system. A major goal of the project is the enforcement of patient centered medicine [3], standardization, and transparency of medical treatment. A commission, having equal representation of health insurances, medical associations, and government, has worked out the top-down specification [4] to guarantee universal accessibility of standardized data across institutional boundaries to ensure reduction of healthcare costs by avoiding redundant examination and administration in the public health system [5]. According to calculations, Telemedicine services provide added value of between $€ 7.5$ and 29.5 billion over 10 years, calculated from the project kick off date. The annual marginal net utility is supposed to be up to $€ 2.5$ billion, a break-even for the national TI that was estimated after about 5 years [6]. Major use was expected from the electronic medical services: pharmaceutical drug safety, insurance data maintenance, emergency records, and electronic healthcare records (EHR). Further benefits can result from value added applications, using the infrastructure services and the provided medical services.

EHR are an important e-health concept for shared medical documentation, where data objects of care providers' local Electronic Medical Records (EMR) can be conditioned to communicate with other care providers in order to maintain, review or share medical data objects. As nationwide shared medical documentation has not yet been achieved, we focus on one important user group of EHR, ambulatory physicians, to investigate their requirements, concerns and challenges with regard to EHR adoption. Previous surveys have shown that a vast majority of physicians rejects electronic telemedicine services offered by the national TI $[7,8]$. Numerous campaigns have been started by medical associations and politicians, calling for a moratorium on national telematics initiatives with central storage [9]. The main reasons for rejection of these initiatives, as indicated by the objectors, are safety concerns regarding central storage of patients' medical data. This reaction can be regarded as a common pattern for national EHR-initiatives, a reaction which negatively affects attitudes toward EHR to such a degree as to render any national efforts unachievable [10]. Care providers can be grouped into supporters and rejecters of EHS [11], rejecters are a minority in Germany but have significant influence.

Ambulatory care is an important part of medical care delivery, but the utilization of connected information systems is still very low. Seventy-eight percent of physicians in American ambulatory care are working in practices with less than 10 care providers. The adoption of 
advanced and even basic EHR systems is very low in small practices. Only $3.1 \%$ have adopted advanced EHR systems which connect medical documentation across different institutions [12]. Smaller practices show lower adoption of connected medical records than do larger institutions. It is therefore important to analyze how Germany's top down approach, which connects different care providers via a national network, works for small practices. Especially after the failure of the British efforts to build a national EHR-centered telematics [13], content and deployment structures are important, as they play a key role in user acceptance. As the deployment of EHR needs to be included in the changes in the health system [14], this paper evaluates which data the ambulatory care providers need to exchange and how the technology should be provided.

\section{Classification OF EleCtronic Health}

\section{RECORDS IN THE CONTEXT OF HEALTHCARE TELEMATICS}

\section{A. Classification Electronic Medical Records}

To clarify the naming of electronic documentations in healthcare, Fig. 1 groups the records according to three dimensions: the maintenance and administration perspective, the storage location perspective, and the target audience perspective.

- The Electronic Medical Records (EMR) comprise local documentation, which is created, maintained, and used by one medical institution and does not have any patient access. Several EMR exist within the public health system without being synchronized.

- Electronic Health Records (EHR) contain the lifelong medical information of a patient, and consist of shared medical documentation which can be accessed by several health care providers.

- $\quad$ Electronic Case Records (ECR) comprise a context oriented selection of data for a specific medical case maintained by several care providers.

- Personal Health Records (PHR) contain the lifelong medical information of a patient and are maintained by patients.

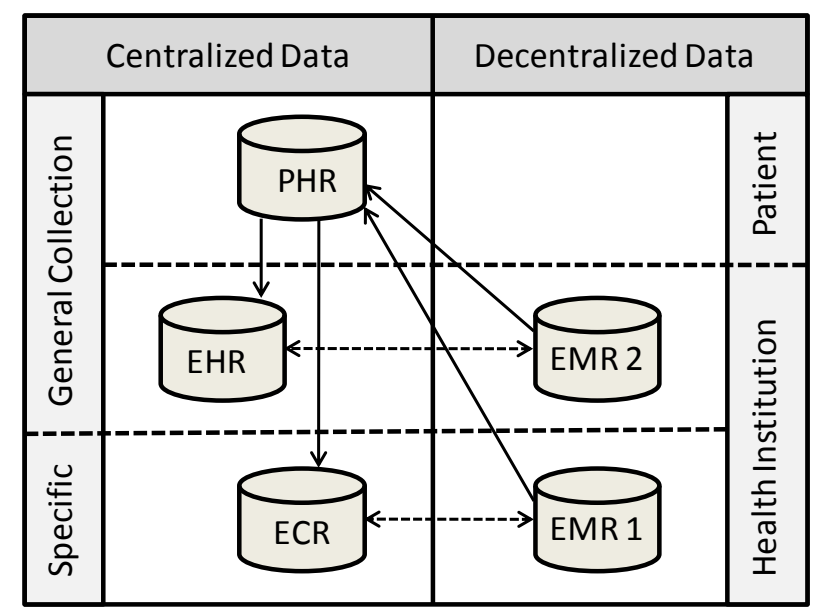

Figure 1. Different naming for medical records.

\section{B. Patient Administration of EHR}

The German code of social law, which aims at the legal implementation of social justice and social security, ensures that medical data can only be processed between care providers with the patients' direct authorization for the receiver [15]. Based on this legal foundation, all national telemedicine initiatives have to implement an authorization mechanism into shared medical documentation as EHR. In order to enable patients to view and authorize every single medical document that is processed between care providers in the public health system, it is essential to enable users to access the EHR [16]. If several care providers maintain a shared comprehensive medical documentation, patients need access to all documents and need to be granted rights to several document selections. This requires not only an access mechanism, but also training and information material. Therefore, it is important to scrutinize patient training for EHR usage, and to highlight which contents of EHR raise skepticism from the care providers' point of view. Patients will select which part of the previous medical documentation can be seen by the care provider, which consequently has an impact on the processes in the public health system. They can, for example, accomplish an additional examination when rejecting physicians in accessing previously created documents.

\section{Naming conventions for Electronic Medical Records}

For centralized storage of health data, various types of local data pools, namely EMR, must be integrated. The national telematics specification defines two kinds of shared health records within telematics: the EHR, a universal set of medical documents, and the electronic case record (ECR), a context oriented selection of data for specific care providers, such as medical specialists. Both are maintained by physicians and controlled by patients [17]. Further, the concept of patient maintained health records, that is, Personal Health Records (PHR), needs to be included in the formal application landscape. To reach the most productive level of Medical Records, according to Waegemann's [18]) definition, the Health Record must contain the lifelong medical information of a patient and hold the information of both patients and health care providers. According to German Law, patients must have the possibility of adding personally generated data to telematics, view all data, delete selected records, and process the content as they prefer. Theoretically, all shared medical records could be named EHR, as they can contain data from care providers and patients. Hence, in German telemedicine, by law, all centralized medical records need also to be PHR, as they need the feature of patients using, adding and removing data from the records. Data are only visible in the EHR after being authorized by the patient in the PHR. This paper uses the term EHR to designate shared records that are maintained and administrated by patients via the PHR. 


\section{RESEARCH FRAMEWORK}

\section{A. Survey Design}

The questionnaire was named "Survey on IT diffusion in ambulatory health care." We investigated the state of information technology in ambulatory practices, with focus on EHR. To reduce the self-selection bias, the questions did not include specific EHR related questions, but general concepts implemented within EHR were asked. The term electronic health card, which raised broad rejection among German physicians, was therefore avoided throughout the questionnaire.

\section{B. Sample Description}

We distributed 500 questionnaires by mail to all physicians in ambulatory care in the Bavarian testing region for healthcare telematics, and provided access to a web-based questionnaire as well. The testing region has 452,000 inhabitants on 2,847 square kilometers. The region is geographically well defined because of its heterogeneous structure, making the region suitable for field testing, as it represents the structure of Germany very well [19]. We received 117 responses, representing a response rate of $23.2 \%$. Only 4 physicians used the online option to submit their results, the remaining 113 returned it by mail. The sample consisted of primary care providers and medical specialists, with the sample divided about evenly between the two groups, albeit with a few more medical specialists. The average practice employs 2.1 physicians and 4.5 other personnel. A physician, on average, is 49.7 years old, and has 46.5 patient consultations per day, each lasting an average of a little longer than six minutes. Each practice is visited by 86.1 patients per day. The structural data does not significantly differ from the available data for the whole of German ambulatory care [20].

TABLE I. STRUCTURAL DATA

\begin{tabular}{|c|c|c|}
\hline $\begin{array}{r}\text { Sample: } N=117, \\
\text { Germany: } N=137500\end{array}$ & $\begin{array}{l}\text { Total } \\
\text { Mean }\end{array}$ & $\begin{array}{c}\text { German } \\
\text { Mean }\end{array}$ \\
\hline Age & 49,7 & 52,2 \\
\hline $\begin{array}{l}\text { Gender } \\
(1=\text { Female, } 2=\text { Male })\end{array}$ & 1,70 & 1,61 \\
\hline $\begin{array}{l}\text { Specialization } \\
\text { ( } 1=\text { Primary Care, } \\
\text { 2=Medical Specialist) }\end{array}$ & 1,59 & 1,56 \\
\hline $\begin{array}{l}\text { Number of Physicians } \\
\text { working in the practice }\end{array}$ & 2,1 & NA \\
\hline Patient consultations per day & 46,5 & NA \\
\hline $\begin{array}{l}\text { Average time spend on patient contact } \\
\text { per day (hours) }\end{array}$ & 7,4 & NA \\
\hline Patients visiting the practice per day & 86,1 & NA \\
\hline Number of Employees in the practice & 4,5 & NA \\
\hline
\end{tabular}

Self-selection bias might have had limited impact due to the technical focus of the questionnaire. Comparison with national data, which was not available at the time of publication, can help to estimate the impact of the bias, comparing data as Internet access or EMR utilization with the present sample.

\section{RESULTS}

\section{A. Supply of EHR Technology to Ambulatory Care}

Table I shows that German ambulatory care is delivered mainly by care providers in small practices, the mean size of which is 2.1 physicians. As is evident from Table II, the vast majority uses EMR and has Internet connection available. About half of the respondents exchange medical data conventionally with emails or fax machines. More than half of the physicians want to use EHR, even though numerous physicians do not see significant advantage compared to the current handling with EMR. The high number of missing answers indicates that many respondents are not able to judge the advantages of EHR. Most participants are not able to oversee the impact that EHR will have not only on their own practice, but also on the public health system. The sections that were answered indicate interest in both, the introduction of EHR for the public health system and for their own practice.

TABLE II. EHR BASIC DATA

\begin{tabular}{lcc}
\hline \multicolumn{1}{|c}{ N=117 } & Mean & $\begin{array}{c}\text { Missing } \\
\text { Data }\end{array}$ \\
\hline $\begin{array}{l}\text { Practice with Internet access } \\
\text { Practice uses Electronic Medical }\end{array}$ & $\mathbf{0 , 7 9}$ & $\mathbf{5}$ \\
Records (EMR) & $\mathbf{0 , 7 7}$ & $\mathbf{6}$ \\
\hline $\begin{array}{l}\text { Practice exchanges medical information } \\
\text { electronically with other institutions }\end{array}$ & $\mathbf{0 , 4 6}$ & $\mathbf{5}$ \\
$\begin{array}{l}\text { Physician uses } \\
\text { email to consult patients }\end{array}$ & $\mathbf{0 , 2 6}$ & $\mathbf{6}$ \\
\hline $\begin{array}{l}\text { Physician would like to use } \\
\text { EHR in his/her practice }\end{array}$ & $\mathbf{0 , 5 7}$ & $\mathbf{2 6}$ \\
$\begin{array}{l}\text { EHR usage would have few advantages } \\
\text { compared to the current handling }\end{array}$ & $\mathbf{0 , 5 5}$ & $\mathbf{4 1}$ \\
\hline $\begin{array}{l}\text { EHR usage would have a big } \\
\text { influence on the practice }\end{array}$ & $\mathbf{0 , 6 7}$ & $\mathbf{6 5}$ \\
\hline $\begin{array}{l}\text { EHR usage would substantially change } \\
\text { the public health system }\end{array}$ & $\mathbf{0 , 6 3}$ & $\mathbf{6 1}$ \\
\hline
\end{tabular}

A set of external services has to be provided in order to utilize the technology in the practices, as they are normally too small to allocate the resources internally. Hence, aspects such as medical service proposition and delivery, hosting of health data, patient and health care provider support are a focus that are essential for IT diffusion of ambulatory care in the future. To evaluate which institutions are trustworthy providers of those offers, we asked the following questions. 
- Who should provide telemedicine services to care providers in the ambulatory field?

- Which institution is a trustworthy information source for telemedicine offers?

- Who is responsible to educate patients in the context of telemedicine offers?

- Who should host patients' medical data?

1) EHR offers to physicians: As seen from Fig. 2, most physicians do not want to buy or obtain IT Services directly from private companies, which is probably due to the small size of institutions in the ambulatory care. Health insurances and health authorities are also not the preferred source.

Likely due to financial dependencies between authorities, insurances, and care providers, the trust might be limited as care providers feel the threat of observation. Medical networks and associations are the providers of choice. Physician networks show the highest support rate, as nearly half of the physicians want to obtain EHS from them. Trust in local structures could be a reason, especially since they are most familiar with the requirements. Thirtyfive percent do not want any EHR related offers. The results imply that physician networks and medical associations will have to play a key role in the supply of EHR to their members.

\section{Who should offer EHS and EHR to physicians}

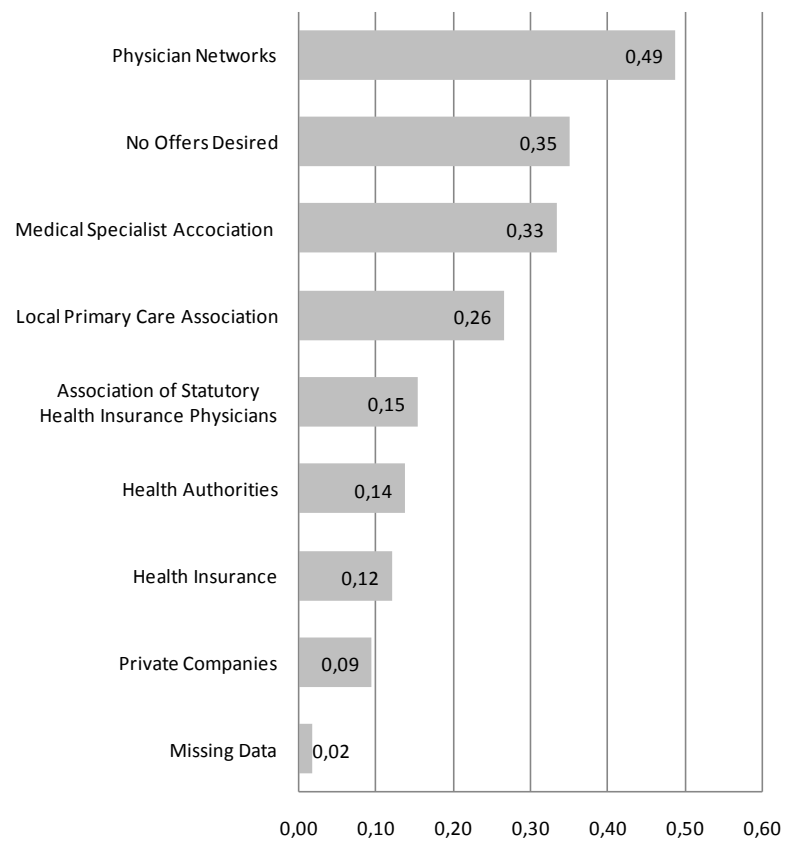

Figure 2. EHR and EHS offers.

2) Patient education: The requirement for the patient administration of EHR presupposes that patients have skills and knowledge to independently operate such systems. Who will assist patients to be able to handle the administrative requirements that they will have to fulfil in the future? The main responsibility for enabling patients to handle the records by EHR related education, as seen in Fig. 3, is carried by health insurances, physicians, patient organizations and the public health authorities. Patient education can therefore be considered a joint effort of all involved parties, with medical associations having less support for direct patient education. Over half of the respondents see a responsibility for the physicians, thus the physicians are not just medical consultants for their patients, but increasingly also feel responsible for process coordination and IT-support. How to synchronize health insurances, physicians, patient organizations and health authorities seems an important task in order to avoid opposing tendencies in patient education.

\section{Responsible institution to educate patients concerning EHR usage}

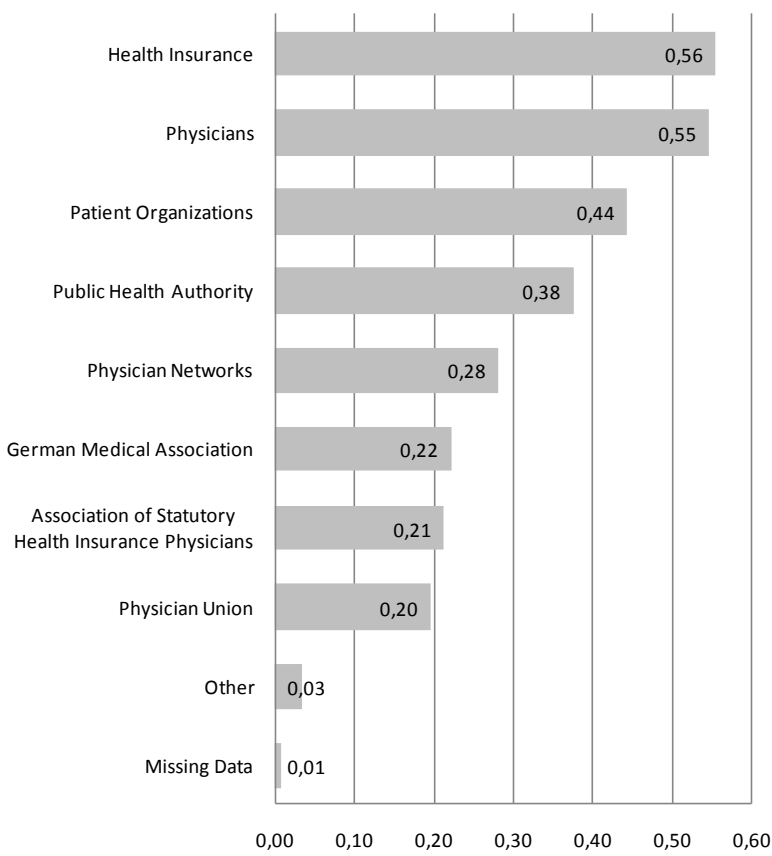

Figure 3. Patient education.

3) Content provider: The usage of EHS requires specifications, usage policies and user manuals for both patients and care providers. From the answers to the questions regarding trustworthy information providers for Health-IT, we can infer that, apart from scientific institutions, physicians regard their occupational organizations as the only information sources to be trusted. Health insurances are not trustworthy sources of EHR related information. Private companies and the gematik (German national health IT organization, maintenance and development of the electronic Health Card) are referred by only very few physicians. BITKOM (Federal Association for Information Technology, Telecommunications and New Media) was not chosen at all. Medical associations and physician unions will have to play a key role in offering comprehensive information on how to handle shared medical documentation. As BITKOM has mainly technical focus by now, we 
conclude that the medical aspects are considered to be more important than the IT related information.

\section{Trustable sources for EHR related information and guidelines}

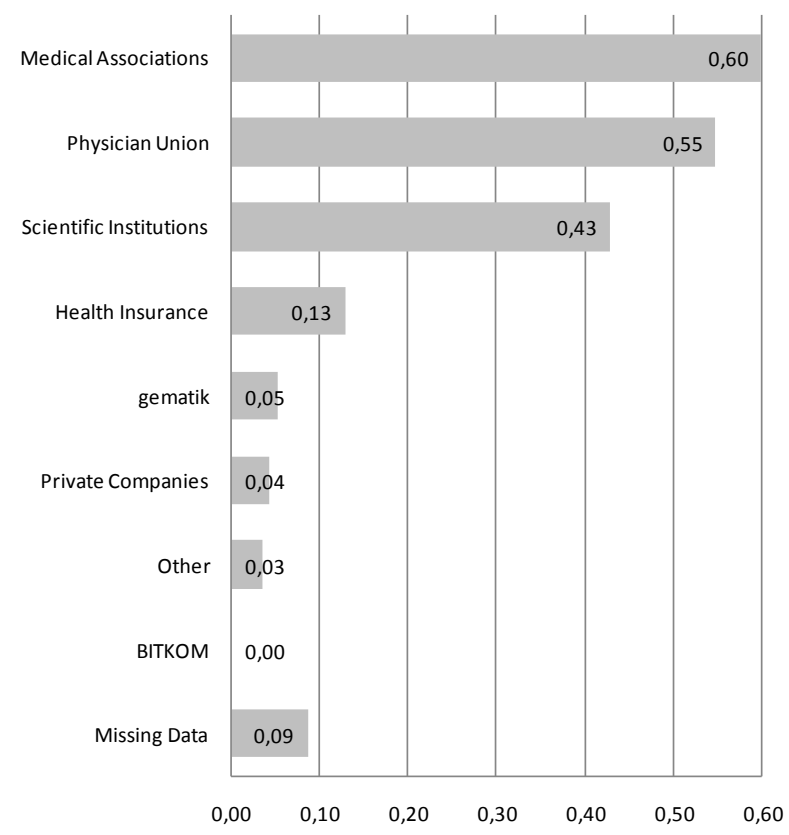

Figure 4. Trustworthy information sources.

4) Hosting of medical data: Central storage is rejected by more than $50 \%$ of the respondents.

\section{Trustable institution to host patients' medical data}

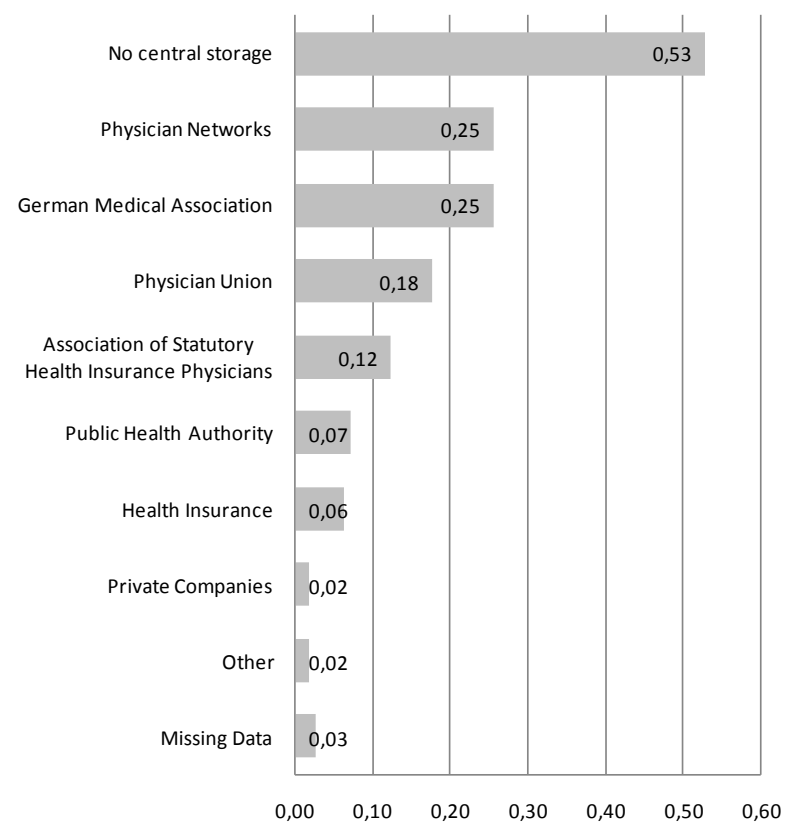

Figure 5. Hosting of medical data.
Those who are in favour of central storage prefer Physician Networks and the German Medical Association to be in charge of the storage. Storing medical data on servers of private companies, health insurances or health authorities is strongly rejected. As central storage turns out to be a major concern, the following section scrutinizes which contents raise the concern of the care providers.

\section{B. Content of EHR}

The previous section indicated that central hosting and data processing by non medical personnel is mostly rejected by respondents. To scrutinize previous findings, we investigated whether all medical data were disputed, or whether only several items raised concerns. If only some parts of the EHR content were unsuitable for exchange between physicians or processing by patients, those could be excluded from the centralized EHR. Alternatively, these items could be either stored locally or processed with decentralized EHR, as USB drives. We therefore provided a matrix with a combination of common EHR content and key medical questions of the German public health initiatives. Medication, Allergies \& Intolerances, Diagnosis, Examination Results, Lab Results, Vaccines Record, Blood Type, Organ Donor Card, DNR Order, Emergency Data were included in the survey. We tested the medical content with the following items:

- Common documentation standards

- Storage in an EMR

- Storage on a central server

- Medical usefulness

- Administrative usefulness

- Electronic transmission to other care providers

- Patient involvement and authorization

- Legal security when processing the data

Regarding the preferred content of electronic health records, we wanted to know how physicians, the main users of EHR, defined the content of EHR, and what their medical and organizational requirements looked like.

1) Clinical data: National documentation standards are generally welcome within the EHR, apart from examination results; the majority rejects documentation of their examinations in a commonly accessible way. The use of medical data exchange for treatment success and administrative benefits is not disputed. According to the respondents, all items in this section, Medication, Allergies \& Intolerances, Diagnosis, Examination Results, Lab Results, have the potential to improve the treatment quality and reduce administrative effort when being exchanged. Due to privacy and legal concerns, physicians discourage patients from centrally storing examination and lab results and diagnosis. Clearly undisputed are central storage and exchange of medication records, as well as allergies and intolerances of patients. The highest potential for medical and administrative improvements is also seen for these items. The German PHR concept, which allows patients to 


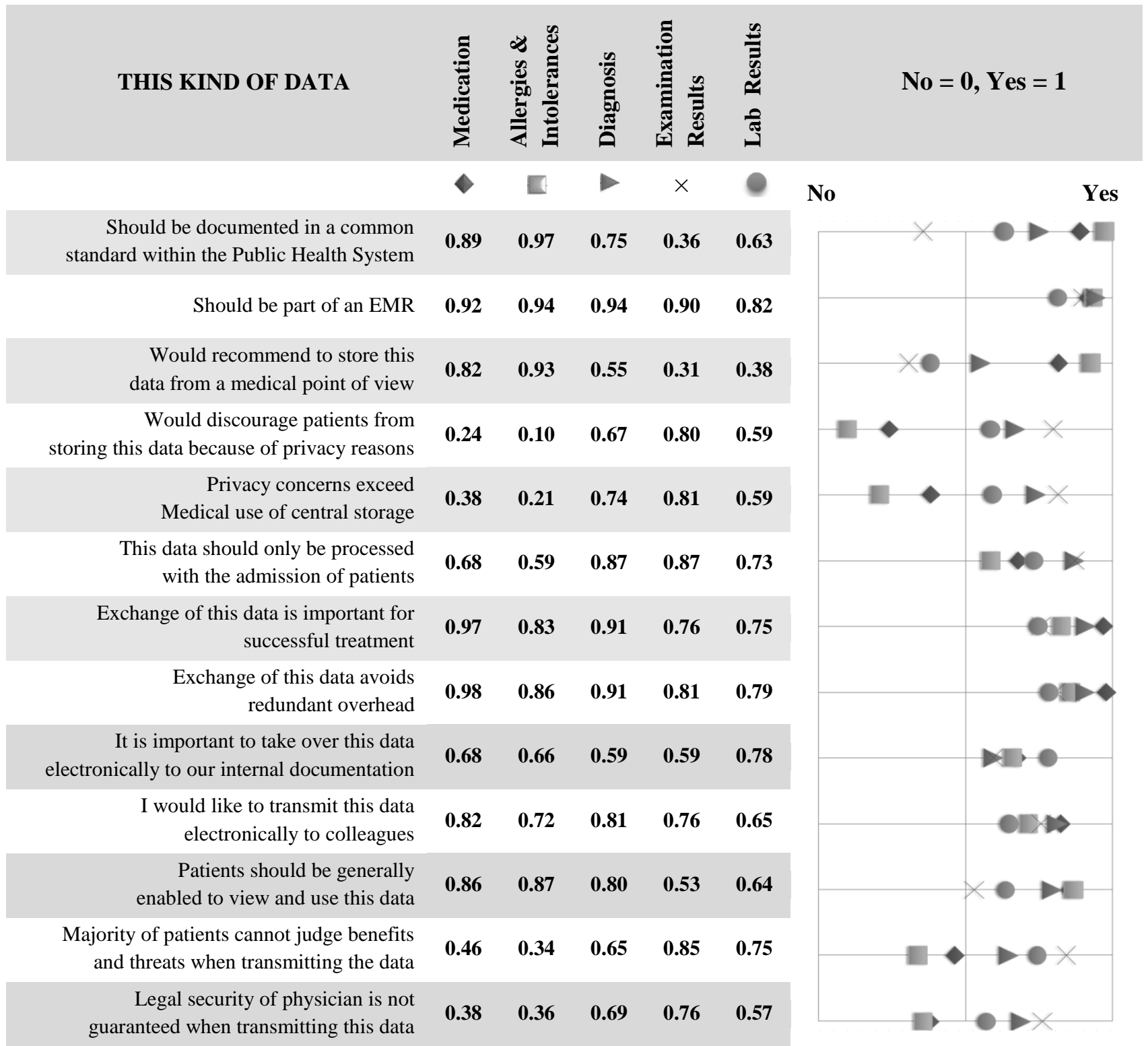

Figure 6. Clinical data and EHR concepts.

view all stored medical data, is generally not disputed. Electronic transmission of all items to other physicians is important to the respondents, as well as the interoperability with their local information systems. The patients' transmission, granted by German law, is not seen positively for lab and examination results, nor for diagnosis. The physicians do not see patients as being able to judge the benefits and threats independently. Interestingly, the answer patterns for privacy concerns and legal security of physicians are very similar. This could indicate that the security concern is a pretense, which reflects the threat of observation of the physicians' work. National EHR initiatives could therefore be implemented as a centralized service, excluding examination results and diagnosis at first. This could reduce the resistance significantly, as many parts of the EHR are not disputed, and data exchange and seamless data availability are generally seen as important improvement features.

2) Further medical content: All items measured in this section, Vaccines Record, Blood Type, Organ Donor Card, DNR Order and Emergency Data, can be documented in EHR without major privacy and legal concerns.

However, except for Emergency data, most physicians do not consider the data exchange between physicians necessary for successful treatment, would however by majority recommend patients to store this data, even though reduction of administrative effort is not obvious to them. Vaccines records and emergency data are seen as a part of the EMR, with emergency data having the highest medical and administrative potential. 


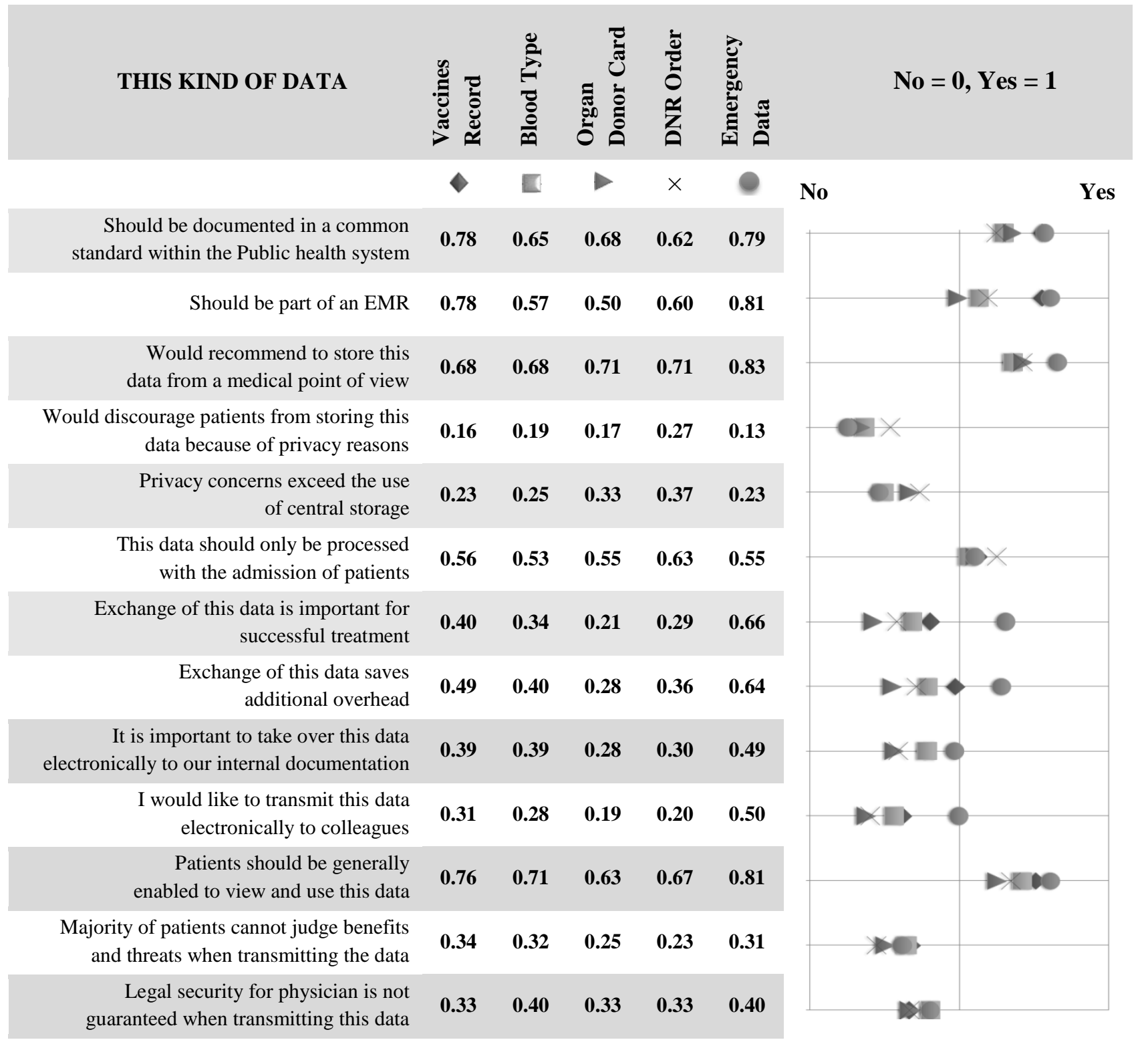

Figure 7. Medical Data objects and EHR concepts.

\section{DISCUSSION AND OUTLOOK}

The usefulness of EHR is mostly undisputed by ambulatory physicians in Germany. Exchange of medical data is considered necessary for the treatment success and reduction of administrative overhead. Exchange of medication, allergies and intolerances are not a point of concern and have, according to the respondents' opinion, the highest improvement potential for the public health system. Vaccines records, blood type, organ donor cards, and DNR order do not raise security concerns either, but the use of exchange is regarded limited, compared to the current handling. Having emergency data seems to be a useful feature, without major privacy concerns. These items can be included into national EHR projects at first, since they are likely to raise little resistance from the physicians' side. Diagnosis, examination and lab results are the main concerns of physicians when it comes to central storage in EHR and patients' involvement into the treatment and authorization process. Physicians are afraid of legal consequences when publishing data as examination results to colleagues and patients. These items seem to be the root of the resistance against centralization of medical data storage. Decentralized storage or point to point exchange should be considered for this kind of data. The usefulness of exchanging data like diagnosis, examinations, or lab results is not doubted in general, that is, only the patient centered administration of it is viewed skeptically. Regarding an EHR as a holistic entity seems therefore inappropriate, as the project is threatened because of very few items to be stored in the centralized record. A modular design of EHR eases an incremental rollout.

This paper analyzes in dept, why safety concerns are such a threat to nationwide efforts to establish comprehensive EHR. The top down approach for healthcare information systems must consider carefully, which parts of the record raise resistance and hand over critical parts to trusted institutions. Neither the state, nor the private economy is a trusted partner 
for medical data hosting and content information delivery. Medical related regional structures seem to be the most trusted institutions for physicians. Physician networks play a key role in a connected health system in Germany as they are the most trusted source. Internationally it is therefore highly recommended to include trusted institutions to planning and operation of national healthcare information systems.

With regard to the fear of misleading processes due to patient involvement and legal concerns, the medical associations have to play a major role as well, especially with respect to hosting, education and offers of EHR. As health insurances, health authorities and private companies are not preferred partners of care providers, a restructuring of the efforts to achieve national health information systems should be considered to source deployment and hosting activities of EHR to medical associations.

It is further obvious that medical associations and physician networks must support physicians, working in facilities with few physicians. They are not able to deliver information, training, administration and handling of EHR systems independently. Physicians consider themselves responsible to enable patients to use EHR properly. Anyhow, physicians must be supported by other institutions to distribute the responsibility of national EHR projects. Comprehensive efforts to build up an information and education program for patients seem to be essential. Medical institutions must provide the EHR related contents for the joint effort to educate patients. Missing differentiated support structures can be a threat to EHR diffusion. Further research should therefore investigate the perceived fear of overload in ambulatory care and the resulting delays.

The low utilization of enhanced EHR systems in the ambulatory care in Germany and the United States are likely to be a result of a missing ecosystem, supporting development, deployment, and operation of EHR. Building organizational structures, which are able to support adoption and improvement of the technology, should be subject of further research to verify the findings in an international context.

\section{REFERENCES}

[1] P. Shekelle, S. C. Morton, and E. B. Keeler, "Costs and Benefits of Health Information Technology," 2006.

[2] Fraunhofer Institut, "Spezifikation der Lösungsarchitektur zur Umsetzung der Awendungen der elektronischen Gesundheitskarte," Fraunhofer, Projektgruppe FuE-Projekt, 2005.

[3] M. Marschollek and E. Demirbilek, "Providing longitudinal health care information with the new German Health Card - a pilot system to track patient pathways," Computer Methods and Programs in Biomedicine, vol. 81, pp. 266-271, 2006.

[4] gematik, "Einführung der Gesundheitskarte - Gesamtarchitektur." vol. 1.5.0: gematik GmbH, 2008.

[5] Bundesministerium für Gesundheit, "The German eHealth Strategy (Target and strategy, concept, legal framework, activities/roll-out plan, costs and return of investment, European perspective)," Berlin/Bonn, 2005.
[6] R. Bernnat, "Kosten-Nutzen-Analyse der Einrichtung einer Telematik-Infrastruktur im deutschen Gesundheitswesen," Booz Allen Hamilton GmbH, 2006.

[7] Techniker Krankenkasse, "Branchenbarometer E-Health," F.A.Z. Institut fuer Management-, Markt- und Medieninformation, vol. 1, 2009.

[8] O. Kalthoff, N. Marsden, S. Kalthoff, and F. Drescher, "Abschlussbericht Evaluation der Einführung der elektronischen Gesundheitskarte in der Testregion Heilbronn," 2008.

[9] A. Tuffs, "Germany plans to introduce electronic health card " BMJ.com Medical publication of the year, 2008.

[10] C. M. Angst and R. Agarwal, "Adoption of Electronic Health Records in the Presence of Privacy Concerns: The Elaboration Likelihood Model and Individual Persuasion " MIS Quarterly, vol. 33, pp. 339-370, 2008.

[11] S. Duennebeil, A. Sunyaev, B. I., J. M. Leimeister, and H. Krcmar, "Do German Physicians want Electronic Health Services? A Characterization of Potential Adopters and Rejectors in German Ambulatory Care," in Third International Conference on Health Informatics (HealthInf 2010), Valencia, 2010, pp. 202-209.

[12] C. DesRoches, E. Campbell, S. Rao, K. Donelan, T. Ferris, A. Jha, R. Kaushal, D. Levy, S. Rosenbaum, A. Shields, and D. Blumenthal, "Electronic Health Records in Ambulatory Care - A National Survey of Physicians," The New England Journal of Medicine, vol. 359, p. 50, 2008.

[13] E. Coiera, "Building a National Health IT System from the Middle Out," Journal of the American Medical Informatics Association, vol. 16, pp. 271-273, 2009.

[14] R. Bashshur and G. W. Shannon, "National Telemedicine Initiatives: Essential to Healthcare Reform," Journal of Telemedicine and eHealth, vol. 15, pp. 600-610, 2009.

[15] Bundesrepublik Deutschland, "Sozialgesetzbuch (SGB) Fünftes Buch, Gesetzliche Krankenversicherung," 1988.

[16] A. Sunyaev, D. Chornyi, C. Mauro, and H. Krcmar, "Evaluation Framework for Personal Health Records: Microsoft HealthVault vs. Google Health," in Proceedings of the Hawaii International Conference on System Sciences (HICSS 43), Kauai, Hawaii, 2010

[17] Bundesministerium für Gesundheit, "Die Elektronische Gesundheitskarte," Berlin, 2008.

[18] C. P. Waegemann, "Current Status of EPR Developments in the US." vol. 1999: Medical Records Institute, 1999, pp. 116-118.

[19] Zentrum für Telematik im Gesundheitswesen $\mathrm{GmbH}$, "Telematik Modellregionen," 2009.

[20] Kassenärztliche Bundesvereinigung, "Grunddaten zur vertragsärztlichen Versorgung in Deutschland," Berlin, 2008. 